\title{
Cs-137 fallout inventories in Iceland - estimating deposition from precipitation data
}

\author{
S.E. Palsson, O. Arnalds ${ }^{1}$, M.A. Sigurgeirsson, J. Guonason, B.J. Howard ${ }^{2}$, \\ S.M. Wright ${ }^{2}$ and P. Palsdottir ${ }^{3}$
}

Icelandic Radiation Protection Institute, Rauoararstig 10, 150 Reykjavik, Iceland

${ }^{1}$ Agricultural Research Institute, Keldnaholt, 112 Reykjavik, Iceland

${ }^{2}$ Centre for Ecology and Hydrology - Merlewood, Grange-over-Sands, Cumbria LA11 6JU, U.K.

${ }^{3}$ Icelandic Meteorological Office, Bustaoavegi 9, 150 Reykjavik, Iceland

\begin{abstract}
Iceland was identified in the Arctic Monitoring and Assessment Report as one of the Arctic areas which received the most global fallout from atmospheric nuclear weapons tests, but measurements of contamination were sparse, and are difficult due to the remote and inaccessible terrain of much of the country. Measurements of global ${ }^{137} \mathrm{Cs}$ deposition have been made at sites close to meteorological stations to ensure that precipitation data were of high quality. The measured data have been compared with different methods of predicting ${ }^{137} \mathrm{Cs}$ deposition. The AMAP modeling approach, based on fallout and precipitation data, was used based on a monitoring station near Reykjavik. The availability of good precipitation data and locally based estimates of time dependent ratios of ${ }^{137} \mathrm{Cs}$ deposition to precipitation during the fallout period gave a better correlation between predicted and observed ${ }^{137} \mathrm{Cs}$ deposition $\left(r^{2}=0.96\right)$ than that achieved using the heterogeneous set of data collected by AMAP over the whole of the Arctic. The method allows a fallout map to be produced for the whole of Iceland for any time period during or after deposition.
\end{abstract}

\section{INTRODUCTION}

Iceland was identified in the Arctic Monitoring and Assessment Programme (AMAP) as one of the Arctic areas which received the most global fallout from atmospheric nuclear weapons tests, due to relatively ligh precipitation rates compared with much of the Arctic and sub arctic [1]. Cs-137 in the Icelandic terrestrial ecosystem almost entirely originates from the nuclear weapons tests carried out in the atmosphere until the early sixties. Fallout was greatest in mid nineteen sixties. Additional fallout from the accident at the Chernobyl Nuclear Power Plant was relatively small [2].

Measurements of fallout from nuclear weapons tests in soil, vegetation and agricultural products started in Iceland over 40 years ago [2]. Considerable variability was present in the results, even between adjacent sites, probably due to the mountainous terrain, changing strong winds and highly variable levels of precipitation. This variability has been especially noticeable in the case of soil samples but measurements of contamination in many areas are sparse, in part due to the difficult, remote and inaccessible terrain of much of the country. The important role of uncultivated rangelands in Icelandic agriculture (for instance in sheep farming) makes it desirable to be able to estimate deposition for many remote areas, as a basis for subsequent estimation of current and future transfer into agricultural products.

The study gave preliminary information on the spatial variation in ${ }^{137} \mathrm{Cs}$ deposition in Iceland, especially in areas used for agriculture. The objectives of the study were (i) to measure the spatial variation of radiocaesium inventories in soils in Iceland and (ii) to compare the results with different approaches to predicting ${ }^{137} \mathrm{Cs}$ contents in soil. This quantification is a necessary first step in an evaluation of vulnerability to radiocaesium deposition in Iceland. It is anticipated that Icelandic soils could be highly vulnerable to radiocaesium due to their volcanic nature and consequent lack of illitic minerals [3], as has been suggested by initial chemical studies on the properties of soils in the Nordic countries [4]. 


\section{SITE DESCRIPTION}

Soils in Iceland are unique amongst soils of Northern Europe. The terrain is mountainous and receives highly variable levels of precipitation. Volcanic eruptions are frequent, and volcanic ash deposits are widespread. In addition, there are vast unstable sandy areas near glacial margins and along floodplains of glacial rivers. Soils that form in materials that are rich in volcanic ash are called Andosols. These soils have low cohesion but can absorb large quantities of water ( $>100 \%$ on dry weight basis). This high water holding capacity intensifies freezing effects that result in solifluction, landslides, needle ice formation, and the formation of hummocks. The very uneven surface of the rangeland areas and sparse vegetation can make it very difficult to obtain representative deposition estimates with soil sampling.

\section{MATERIAL AND METHODS}

\subsection{Precipitation and fallout data}

Measurements of the fallout radioactivity in precipitation have been carried out regularly in Iceland for a station close to Reykjavík (Rjúpnahæð, code in this paper: RJU) since 1958 [2]. These measurements were conducted by the United Kingdom Atomic Energy Authority in Harwell since April 1959. The precipitation data used in this study comes from the Icelandic Meteorological Office and are regularly reported in its journal [5]. The journal also gives values from the United Kingdom Atomic Energy Authority in Harwell for ${ }^{137} \mathrm{Cs}$ activity concentration in precipitation from April 1959 to (and including) 1982. Therefore, this site was used as the base station for deriving the quarterly ratio of ${ }^{137} \mathrm{Cs}$ fallout to precipitation in Iceland, using the AMAP methodology outlined by Wright et al. [1]. The data from the base station, RJU, shows that $82.9 \%$ of the decay corrected deposition of ${ }^{137} \mathrm{Cs}$ in the period $1960-1982$ occurred during the first eight years 1960-1967. The emphasis in this study was therefore placed on meteorological stations that had been in operation during these eight years; deposition for these years was estimated based on precipitation data for this period. These results were subsequently scaled up to the period $1960-1982$, assuming that in all cases $82.9 \%$ of the deposition had occurred during the first eight years used for calculations. Fallout data from before 1960 has not been taken into account in this study and thus the measured values should be slightly higher than those predicted.

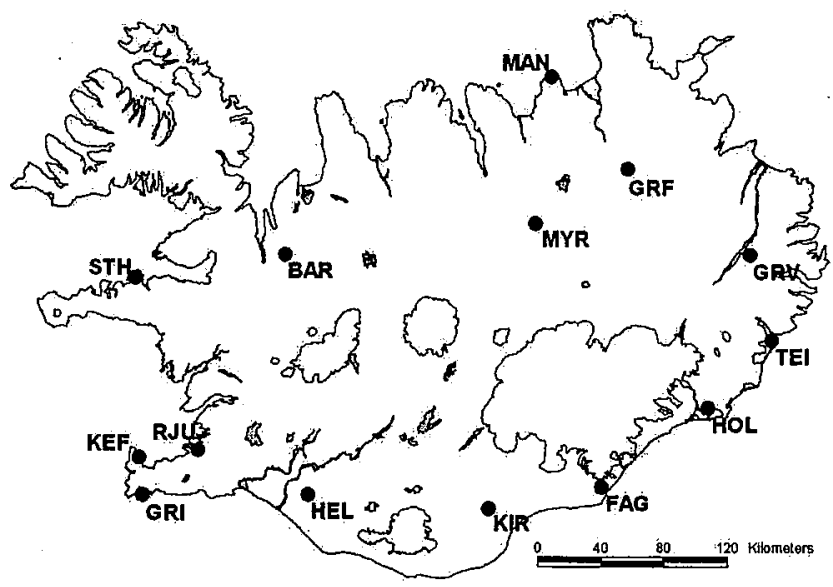

Figure 1. Soil sampling sites used in this study. Each site is identified with a 3 letter identification code, cf figure 2.

\subsection{Soil sampling}

Measurements of radioactive fallout in soils have been carried out by the Icelandic Radiation Protection Institute (IRPI) since 1989. In autumn 2000, IRPI started systematic analysis of radiocaesium in Icelandic soils. Soil samples from 14 sampling sites were collected in 2000 . The sampling sites were 
deliberately located close to meteorological measurement stations so that good representative data was available on precipitation for each sampling site, and the exact location of each site was recorded using a GPS instrument (Figure 1). The sites were selected so that they would span a range of precipitation rates as well as representing different areas and soil types. Soils were sampled with 17 and $19 \mathrm{~mm}$ diameter sampling probes to a depth of up to $30 \mathrm{~cm}$. Twenty cores were collected at each site at 1 metre intervals along a $20 \mathrm{~m}$ long transect and bulked. A more detailed description of the procedure adapted can be found in a report on sampling procedures in use in the Nordic countries [6].

\subsection{Radiocaesium measurements}

The activity concentration of ${ }^{137} \mathrm{Cs}$ was measured using HPGe spectrometry and estimated on an activity per unit area basis $\left(\mathrm{kBq} \mathrm{m}^{-2}\right)$.

\subsection{Cs-137 deposition estimates}

Various authors have linked ${ }^{137} \mathrm{Cs}$ deposition to precipitation $[1,7,8]$. The results are often normalised and presented as amount of deposition per unit area per $1000 \mathrm{~mm}$ annual precipitation. Using annual precipitation rates to predict deposition is based upon the assumption that the deposition is proportional to the average precipitation rate. This means that estimates of deposition can be made having one reference site where deposition is known, deposition at other sites can then be estimated by multiplying the reference deposition by the ratio of annual average precipitation rate at each site and dividing by the precipitation rate at the reference site. The time corrected accumulative deposition estimate for the reference site can be based on measurements of ${ }^{137} \mathrm{Cs}$ activity concentration in rainwater and the corresponding amount of precipitation, and it can also e.g. be based on measurements of amount per unit area of ${ }^{137} \mathrm{Cs}$ in soil.

\subsection{Estimating annual precipitation, selection of time interval used for averaging}

The average annual precipitation rate can be calculated in various ways. In areas with highly variable precipitation rates, the value of the calculated average depends on the method used for the averaging. The following methods were used in this study for calculating the average annual precipitation rates:

a) Averaging over 30 years (1931-1960, 1961-1990). The 30 year standard reference time period, $1961-1990$ is often used for reference meteorological data, especially when there is a need to calculate average values for meteorological parameters. The 30 year period, 1931-1960 has previously also been widely used as a reference period.

b) Averaging over 8 years (1960-1967). The same method as (a) apart from that the annual precipitation estimate is based on the 1960-1967 average. This is the time period in which most of the deposition of ${ }^{137} \mathrm{Cs}$ fallout occurred. Calculating an average based on this period should therefore give a better correlation between deposition and precipitation rates.

c) Averaging with respect to radiological effects. In (b) the ${ }^{137} \mathrm{Cs}$ activity concentration in precipitation was used to help define the most suitable time window for averaging the precipitation rate. This method can be extended further by calculating the precipitation rate as a weighted average and using the ${ }^{137} \mathrm{Cs}$ activity concentration as the weighting function. No restrictions need to be made concerning the length of the time interval and this method automatically ensures that the calculated average is mainly affected by the precipitation rates in the periods which contributed most to the deposition. This method should be expected to give best results for correlation between precipitation rates and deposition.

The AMAP method. The method used successfully in the AMAP study [1] can be formulated as follows. The deposition at each site is estimated by assuming that the ${ }^{137} \mathrm{Cs}$ activity concentration in precipitation was the same at all sites during any given time period. Thus the deposition at each site can be estimated by measuring the activity concentration of ${ }^{137} \mathrm{Cs}$ in precipitation at one reference site and then estimating the deposition at other sites by summing the product of precipitation (in $\mathrm{m}$ ) at the site and ${ }^{137} \mathrm{Cs}$ activity concentration in precipitation (in $\mathrm{Bq} \mathrm{m}{ }^{-3}$ ) at the reference site for time periods of interest. 
The AMAP method can be shown to be equivalent to method (c) described above, averaging with respect to radiological effects.

\section{RESULTS}

\subsection{Effects of methods of averaging}

The average annual precipitation at the Rjúpnahæo reference site is therefore $28 \%$ higher if it is calculated as a simple average of the years 1931-1960 than if the averaging is based on the radiological effects (method c).

Table 1. Effect of method of averaging annual precipitation at the Rjúpnahæo reference site

Method used for averaging Average annual precipitation $\left(\mathrm{mm} \mathrm{y}^{-1}\right)$

\begin{tabular}{cc} 
Average of the years 1931-1960 & 1026 \\
Average of the years 1961-1990 & 984 \\
Average of the years 1960-1967 & 870 \\
to radiological effects (method c) & 802 \\
\hline
\end{tabular}

\subsection{Cs-137 inventories and Correlation between measured and predicted ${ }^{137} \mathrm{Cs}$ deposition}

The measured ${ }^{137} \mathrm{Cs}$ content per unit area of soil varied from $900-4700 \mathrm{~Bq} \mathrm{~m}^{-2}$, with higher deposition in the south of Iceland which receives more precipitation. There are various ways of estimating the correlation between predicted and measured values for ${ }^{137} \mathrm{Cs}$ deposition. The method used in the comprehensive AMAP study [1] was to force the regression line to go through the origin and calculate correlation coefficients on that basis. This approach will give a considerably higher value for the correlation coefficient than for an unbound regression line, but it can be justified on the basis that the assumption being tested is that deposition is directly proportional to precipitation. This same approach was used in this study. A comparison of measured and predicted values for each site is shown in Figure 2. In all cases the estimates for the period 1960-1967 were scaled up to be applicable for the period 19601982 as described previously.

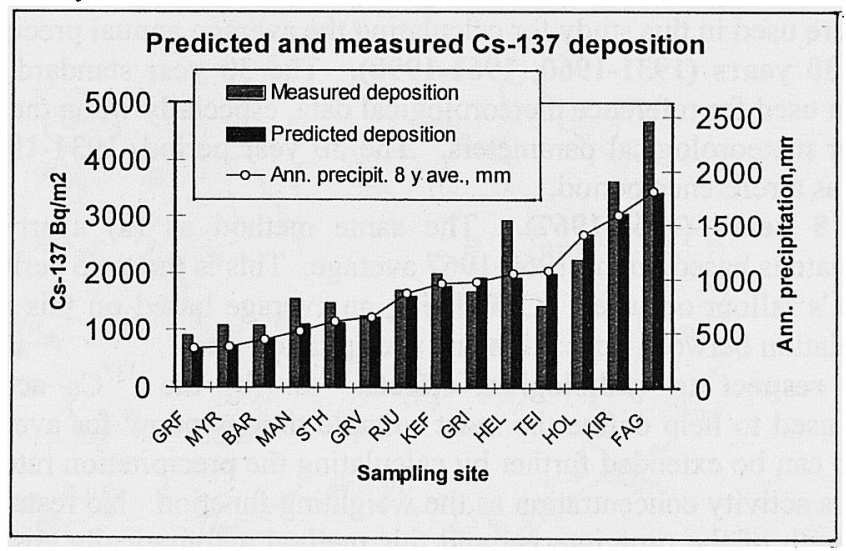

Figure 2. Comparison of predicted ${ }^{137} \mathrm{Cs}$ deposition based on precipitation data and measured values at 14 sites close to meteorological stations in Iceland. The annual precipitation was calculated by averaging with respect to radiological effects (method c). The annual precipitation is also shown as an 8 year average (1960-1967).

The correlation between measured and predicted values (using method c) for ${ }^{137} \mathrm{Cs}$ deposition was good for all sampling sites $\left(r^{2}=0.96\right)$ (Figure 2). The figure shows that the predicted values are also highly correlated with the annual average precipitation at each site, based on the years $1960-1967\left(r^{2}=\right.$ 0.96) (method b). Using the 30 year standard reference period 1961-1990 gave a poorer correlation $\left(\mathrm{r}^{2}=\right.$ 0.93 ) (method a) as expected. 


\section{DISCUSSION}

Two methods of fallout prediction were considered. Firstly, a simple ratio approach (corresponding to methods (a) and (b) in section 3.5) was used based on published values for the amount of ${ }^{137} \mathrm{Cs}$ deposited per $1000 \mathrm{~mm}$ precipitation of $10 \mathrm{pCi}$ per $\mathrm{cm}^{2}$ per $1000 \mathrm{~mm}$ precipitation for samples collected in 1977 (equivalent to $3.7 \mathrm{kBq} \mathrm{m}^{-2}$ ) by Cawse and Horrill [7] for sampling conducted in 1977 in the UK. Lillegraven and Hvinden reported in 1966 [8] a corresponding, earlier estimate of $3.23 \mathrm{kBq} \mathrm{m}^{-2}$ per 1000 $\mathrm{mm}$ precipitation in Norway, however, this does not cover the entire period we have specified up to 1967.

An alternative approach was to use a model predicting deposition using precipitation data, in a similar manner as that used previously within the Arctic Monitoring and Assessment Programme (AMAP) [1]. This corresponds to method (c) as described in section 3.5. In the AMAP analysis, the annual ratio between ${ }^{137} \mathrm{Cs}$ fallout and precipitation was derived for a base station (Tromsø) and the prediction spread over the Arctic using a precipitation data set with a resolution of $0.5^{\circ} \times 0.5^{\circ}$. Wright et al. [1] gave an estimate of $3.69 \pm 0.97 \mathrm{kBq} \mathrm{m}^{-2}$ per $1000 \mathrm{~mm}$ precipitation for the end of 1985 . The values given above are quoted for different years. To be able to compare the values, we have decay corrected them to the end of 2000 when the Icelandic samples were taken. The results can be seen in Table 2 and vary from 1.8 to 2.6 .

Table 2. Comparison of estimates of normalised deposition to precipitation ratios, time corrected to end of 2000

\begin{tabular}{lc}
\hline Source of data & $\begin{array}{c}\mathrm{kBq} \mathrm{m}^{-2} \text { per } 1000 \mathrm{~mm} \\
\text { decay corrected to end of } 2000\end{array}$ \\
\hline Wright et al (AMAP) & 2.6 \\
Cawse and Horrill & 2.1 \\
Lillegraven and Hvinden & 1.8 \\
This study, predicted estimate & 2.0 \\
This study, measured in soil & 2.4 \\
\hline
\end{tabular}

The results of this study agree with the first two studies, taking into account the stated uncertainties of those estimates and that the measured values in the Icelandic study were slightly higher than those predicted.

The comparison of predicted and measured values for Iceland was much stronger than that originally reported by Wright et al [1]. In the AMAP study, data were analysed for 50 samples from Greenland, Norway and Russia from the period 1961-1985. A line through the origin was fitted to the data set using least squares regression giving an $\mathbf{r}^{2}$ value of 0.51 [1] based on a coarse precipitation data set, disparate sources of measured ${ }^{137} \mathrm{Cs}$ deposition using different sampling methodologies. In Iceland, a comparison of predicted and measured values gives a corresponding $\mathrm{r}^{2}$ value of 0.96 . This same correlation was obtained, both when the AMAP method was used (method c) and when the prediction was based on average annual precipitation for the years 1960-1967 (method b). Some of the improved correlation compared with the AMAP study is probably due to the proximity of meteorological stations, where precipitation has been measured in a consistent manner. Furthermore, the soil sampling was conducted by the same team, with a consistent, rigorous methodology over a short period of time. However, the strength of the correlation is surprising considering that dry deposition is not accounted for in the method, although because of the high precipitation rate in much of Iceland dry deposition may not be expected to be an important contributor to total ${ }^{137} \mathrm{Cs}$ deposition. In addition, lateral transport by erosion would be expected to occur in some Icelandic areas [9]. Consistent methodology of soil sampling and compiling precipitation data can be crucial for successful application of precipitation based deposition estimates

The prediction based on the average annual precipitation for the years 1960-1967 (method b) gave a higher correlation with measured data than expected. The probable explanation for this is the highly correlated precipitation pattern between these stations, due to their proximity. This can be seen, for example, if the precipitation pattern as a function of time for all the stations is plotted. The method could thus be expected to provide significantly poorer results than the AMAP method, when applied to a larger geographical area with a less correlated precipitation pattern. 
Overall, the AMAP methodology has been successful and has the advantage that it is possible to predict the ${ }^{137} \mathrm{Cs}$ deposition at any location in any year after 1960 , even though fallout prior to this year was occurring but at lower levels than those prevailing in the nineteen sixties. This study will be followed up, investigating sites near and further from meteorological stations, including some sites where erosion might occur. The next step will be to use this methodology to create a map of ${ }^{137} \mathrm{Cs}$ deposition across Iceland and to test the predictions.

\section{ACKNOWLEDGEMENTS}

The study is carried out in co-operation between the Icelandic Radiation Protection Institute, the Agricultural Research Institute and the Icelandic Meteorological Office. This study is a part of the NKS/BOK-2 project and has received support from the NKS through the project. Co-operation with CEH occurred under the International Union of Radioecology task force on Arctic and Antarctic ecosystems.

\section{REFERENCES}

[1] Wright, S. M., Howard, B. J., Strand, P., Nylén, T. and Sickel, M. A. K.: Prediction of ${ }^{137} \mathrm{Cs}$ deposition from atmospheric nuclear weapons tests within the Arctic. Environ Poll 104 (1999) 131-143.

[2] Pálsson S.E. 1996: Fallout from atmospheric nuclear tests in the sixties - Review of data from Iceland. The 7th Nordic Seminar on Radioecology, Reykjavík, Iceland, 379-384.

[3] Sigurgeirsson, M.Á., Arnalds, Ó., Pálsson, S.E., Gudnason, K. 2000: Radiocaesium (Cs-137) fallout in Iceland and its behaviour in Arctic volcanic soils. The 8th Nordic Seminar on Radioecology, Rovaniemi, Finland, 4 pp.

[4] Oughton, D. Tronstad, E. and Skipperud, L. 1997: Soil mobility: Laboratory studies. In: Technical Report EKO-2.1. TR-EKO-2(1997)1. The sheep project 1996.

[5] Veđráttan, 1959-1983. General reference to Veðráttan, a monthly journal of the Icelandic Meteorological Office. The Icelandic Meteorological Office, Reykjavík, (in Icelandic).

[6] Isaksson, M. 2000: Sampling methods - A survey of methods in use in the Nordic countries. NKS/BOK-1.1, NKS-17.

[7] Cawse, P.A. and Horrill, A.D. (1986) A survey of caesium-137 and plutonium in British soils in 1977. AERE R 10155. Harwell: Oxford.

[8] Lillegraven, A., Hvinden, T., 1982. Measurements of Cesium-137 in Norwegian Soil Samples. FF1/Report-821, 3004. Norwegian Defence Research Establishment, Kjeller (in Norwegian)

[9] Arnalds, Ó. 1999: Soils and soil erosion in Iceland. In: Ármannsson, H. (ed.), Geochemistry of the Earth's Surface, Balkema, Rotterdam, p. 135-138. 